\title{
X-RAY REFLECTIVITY STUDY OF REACTIVE DC SPUTTER DEPOSITED $\mathrm{Al}_{2} \mathrm{O}_{3}$ THIN FILMS
}

\author{
A. BENDER, E. SCHIPPEL \\ Hochschule Wismar, Fakultät Elektrotechnik, Philipp-Müller-Straße, Wismar 0-2400, FRG
}

(Received March 17, 1993; in final form April 12, 1993)

X-ray reflection was performed on $\mathrm{Al}_{2} \mathrm{O}_{3}$ thin films obtained by dc magnetron sputtering of aluminium in an argon/oxygen atmosphere. Two kind of films (amorphous and $\gamma-\mathrm{Al}_{2} \mathrm{O}_{3}$ ) were deposited on polished silicon wafers by conventional sputtering and sputtering with ion bombardment on the growing film. The $x$-ray reflection allows one to determine the surface roughness, mass density and thickness. The thickness was compared with ellipsometry data, and mechanical scanning measurements (stylus method). Transmission electron diffraction investigations were made for phase determination.

\section{INTRODUCTION}

Aluminium oxide is a stable insulator, and $\mathrm{Al}_{2} \mathrm{O}_{3}$ films have several advantages compared with $\mathrm{SiO}_{2}$ films. The mobility of ionic species ( $\mathrm{Na}$ etc.) is very low ${ }^{1}$ and the dielectric constant and refractive index are larger than $\mathrm{SiO}_{2}$ films. If high-quality films are obtained at low deposition temperatures, these films can be used as dielectric films in electronic and optical devices. The low temperature is very important for passivation of metal tracks in thin-film circuits with multilayer structures. Some authors ${ }^{2-4}$ described the reactive magnetron sputtering as a successfull technology for the deposition of $\mathrm{Al}_{2} \mathrm{O}_{3}$ thin films.

In this work, high-quality $\mathrm{Al}_{2} \mathrm{O}_{3}$ films were obtained by reactive dc magnetron sputtering at temperatures of about $100{ }^{\circ} \mathrm{C}$ and high deposition rates. This work gives a short description of the sputtering process in an conventional sputtering apparatus and the idea of ion bombardment leading to a film roughness below the substrate roughness. The purpose of the present work is the application of $\mathrm{x}$-ray reflectivity measurements on reactive dc sputtered $\mathrm{Al}_{2} \mathrm{O}_{3}$ films deposited on polished silicon wafers to determine the surface roughness, mass density, and thickness. The results of the thickness measurements were compared with ellipsometry data and mechanical scanning measurements. In addition, the electrical properties, the index of refraction, and the structure (phase determination) were investigated.

\section{DEPOSITION TECHNIQUE}

The $\mathrm{Al}_{2} \mathrm{O}_{3}$ films were deposited in a standard evaporation apparatus (Hochvakuum Dresden) equipped with an $1 \mathrm{~kW}$ planar magnetron and an oil diffusion pump 
fitted with a cold trap enabling a residual pressure of $2 \times 10^{-4} \mathrm{~Pa}$ to be obtained. The aluminium target $(99.999 \%$ purity, $60 \mathrm{~mm}$ in diameter) was mechanically clamped to a water-cooled copper electrode. A constant current dc supply was connected to the target.

An aluminium vessel was arranged around the magnetron cathode working as a minichamber. Between the cathode and the substrate (distance $70 \mathrm{~mm}$ ) was a shield with defined aperture. The argon inlet was near the cathode and oxygen inlet near the substrate. The shield was used to prohibit the diffusion of oxygen to the target. A stable sputtering process (no arcing) was guaranteed for more than two hours. The sputtering power was $0.6 \mathrm{~kW}$ and a deposition rate of about 18 $\mathrm{nm} \mathrm{min}^{-1}$ was attained during intermittent deposition for six substrate positions. Only three monolayers of aluminium were deposited during every rotation because of the high speed of $1 \mathrm{rev} . / \mathrm{s}$. A full oxidation of aluminium was realized at a low oxygen mass flow of about $4 \mathrm{~Pa} 1 \mathrm{~s}^{-1}$. An additional permanent magnet was mounted above the substrate to stimulate the oxygen molecules. The additional magnetic field caused a modification of the plasma during sputtering. A bright light was visible near the substrate and the target erosions track became larger, but no substrate bias voltage was measured. Thus, we assumed a small bombardment of ions on the growing $\mathrm{Al}_{2} \mathrm{O}_{3}$ film. The substrate temperature was $100{ }^{\circ} \mathrm{C}$ for all deposition processes (with and without ion bombardment). The stoichiometry of the $\mathrm{Al}_{2} \mathrm{O}_{3}$ films was determined by Rutherford backscattering. The ratio was about 3.03:2.00 between oxygen and aluminium. Argon (less than 1\%) was found in both deposited $\mathrm{Al}_{2} \mathrm{O}_{3}$ films.

\section{RESULTS AND DISCUSSION}

\subsection{Electrical Properties, Refractive Index and Phase Determination}

Thin film $\left(\mathrm{NiCr}-\mathrm{Al}_{2} \mathrm{O}_{3}-\mathrm{Al}\right)$ capacitors were prepared on glass substrates for electrical measurements. The conventional sputtered $\mathrm{Al}_{2} \mathrm{O}_{3}$ films were characterized by a dielectric strength $\mathrm{E}_{\mathrm{D}}$ of about $9 \times 10^{5} \mathrm{~V} \mathrm{~cm}^{-1}$, a dielectric loss $\tan \delta$ between $0.6-0.7 \%(1 \mathrm{kHz})$, and a specific resistance $\rho$ of about $3 \times 10^{13} \Omega \mathrm{cm}$. The dielectric constant $\varepsilon_{\mathrm{r}}$ reached a value of 6.2. The capacitors prepared with ion bombarded $\mathrm{Al}_{2} \mathrm{O}_{3}$ thin films had a better dielectric loss $(\tan \delta=0.4-0.5 \%)$ and a higher value of $\varepsilon_{\mathrm{r}}=6.8$. The dielectric strength and the specific resistance did not show any significant differences.

The refractive index $\mathrm{n}$ was determined by ellipsometry $(\lambda=632.8 \mathrm{~nm})$ and reached a value of $1.65 \pm 0.01$. The results of the electrical measurements show that the reactive sputtered $\mathrm{Al}_{2} \mathrm{O}_{3}$ films deposited at low substrate temperatures are suitable for passivation to realize metal-insulator-metal structures in thin-film circuits. The higher values of permittivity and refractive index for the $\mathrm{Al}_{2} \mathrm{O}_{3}$ films prepared with ion bombardment may be an indication of a higher mass density and/or structural differences compared with conventional sputtered $\mathrm{Al}_{2} \mathrm{O}_{3}$. The transmission electron diffraction pattern (see Figure 1 and 2) show differences in the angular reduced intensity distribution function. The intensity function in Figure 1 (conventional sputtered) is characterized by broad maxima, which are typical of 


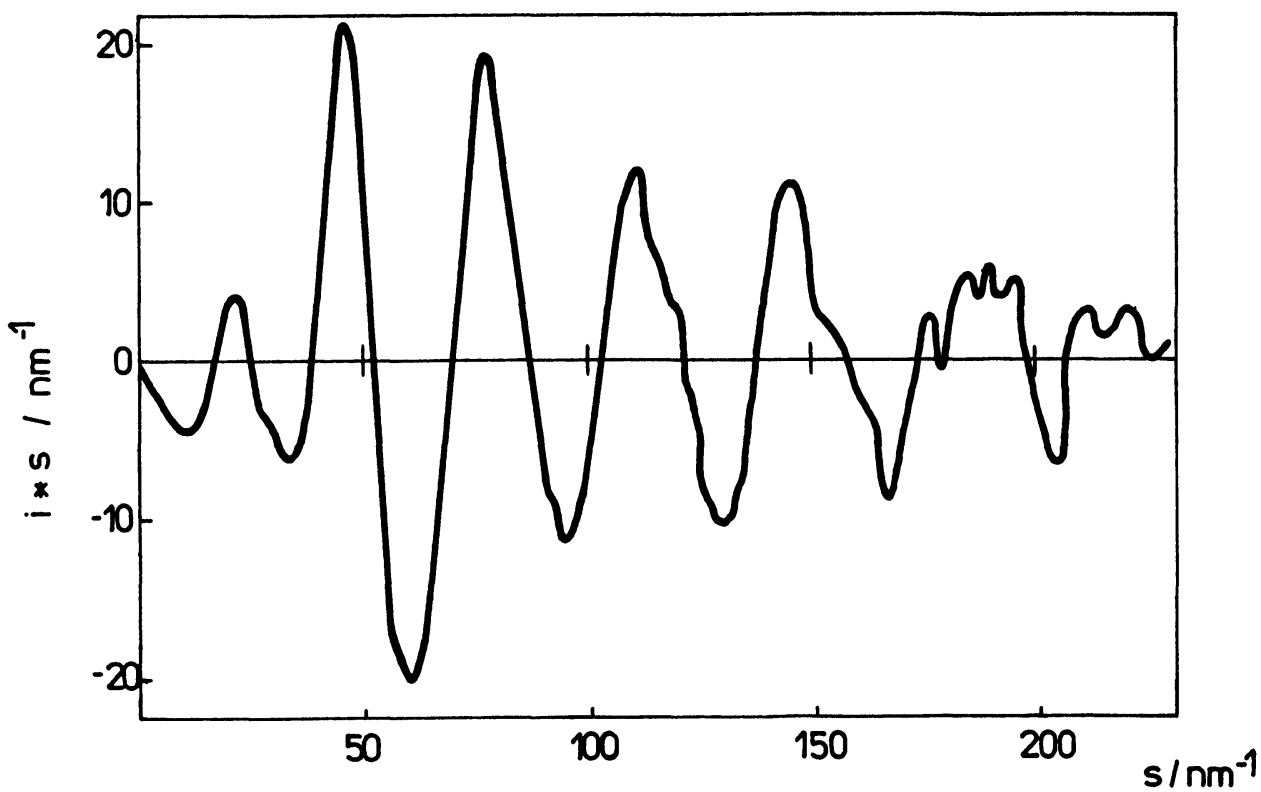

FIGURE 1 Reduced intensity $\mathrm{i}(\mathrm{s})$ (s is the amount of the scattering vector) for amorphous $\mathrm{Al}_{2} \mathrm{O}_{3}$ (conventional sputtered)

amorphous films. Manaila et al. ${ }^{5}$ made $\mathrm{x}$-ray investigation studies on amorphous $\mathrm{Al}_{2} \mathrm{O}_{3}$ thin films. The angular intensity distribution measured by Manaila was characterized by broad maxima at the same position as in Figure 1. Figure 2 (with ion bombardment) shows several sharp maxima, which are typical in their position for low-temperature $\gamma-\mathrm{Al}_{2} \mathrm{O}_{3}$. These results show that a small amount of ion bombardment to the growing $\mathrm{Al}_{2} \mathrm{O}_{3}$ film causes structural changes, which are connected with changes in refractive index and electrical properties.

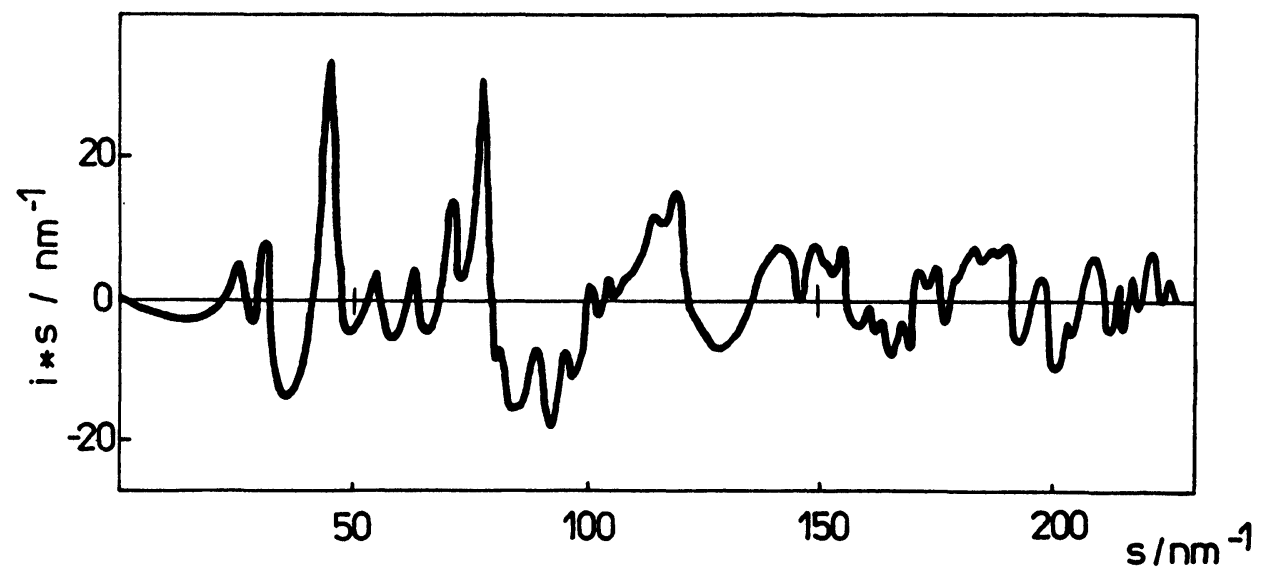

FIGURE 2 Reduced intensity $\mathrm{i}(\mathrm{s})$ for $\gamma-\mathrm{Al}_{2} \mathrm{O}_{3}$ (with ion bombardment) 


\subsection{X-ray Reflectivity}

The $\mathrm{x}$-ray reflectivity analysis as a non-destructive technique for thin film investigation is sensitive mainly to the film electron density distribution normal to the surface. The main application is the detailed determination of the electron density profile, which can be used to calculate the material density. The critical angle $\vartheta_{\mathrm{C}}$ (total external reflection exists) is proportional to the wavelength and the square root of the material is density ${ }^{6}$. The reflectivity can be calculated by using the standard Fresnel equation and the formula given by Paratt ${ }^{7}$. Some methods exist for evaluating the interface roughness. One example is that the localized interface height follows a Gaussian distribution, gives an error function density profile, and results in a Debye-Waller-like term in the reflectivity calculation ${ }^{8}$. In this work, we use the idea reported by Wu et al. ${ }^{9}$. The transition from the film material $1\left(n_{1}\right)$ to the film material $2\left(n_{2}\right)$ takes place in a interface film of thickness $\Delta d$. The thickness $\Delta \mathrm{d}$ is representative for the roughness.

The transition of the refractive index $\mathrm{n}$ follows a tanh as it is seen in the following equation.

$\mathrm{n}(\mathrm{d})=1 / 2\left(\mathrm{n}_{1}+\mathrm{n}_{2}\right)+1 / 2\left(\mathrm{n}_{1}-\mathrm{n}_{2}\right) \tanh (-\boldsymbol{q}+2 \llbracket \mathrm{d} / \Delta \mathrm{d}) \quad \mathrm{d} \in[0, \Delta \mathrm{d}]$

An analytical solution for the calculation of the reflectivity curve can be found by using this equation ${ }^{10}$.

The method allows one to distinguish between interior interfaces (substrate roughness, film surface roughness). The plot of the real part $\delta$ of the complex refractive index $n$ is also to be seen in Figure 3 and 4 .

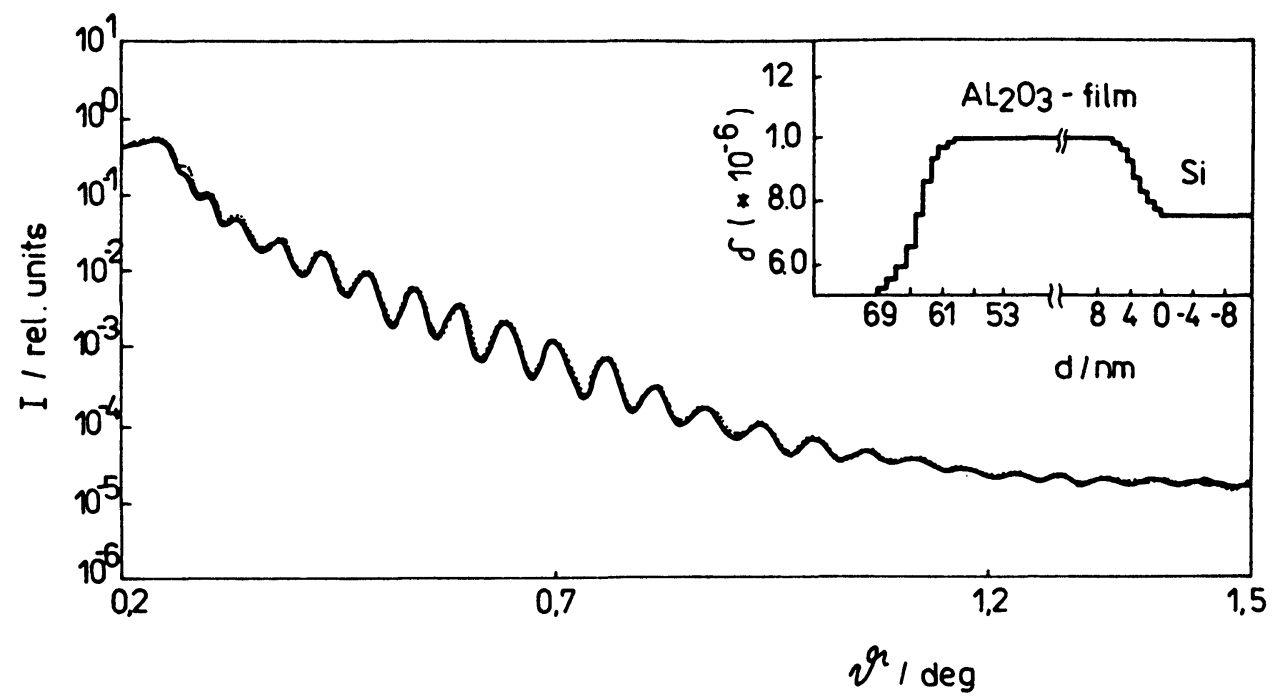

FIGURE 3 -- experimental and simulated reflectivity of $\mathrm{Al}_{2} \mathrm{O}_{3}$ (conventional sputtered) on polished silicon. At the right corner is the real part $\delta$ of the refractive index $\mathrm{n}$ as a function of thickness $\mathrm{d}$ which is used for treating the surface roughness. 


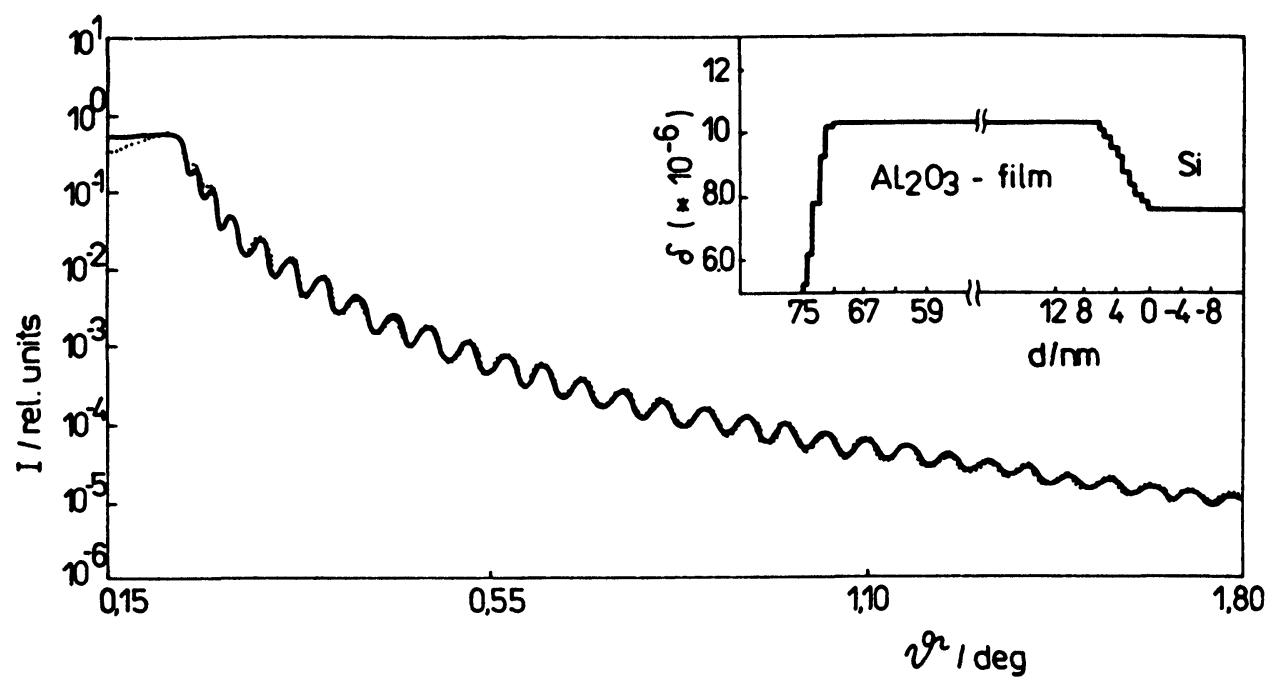

FIGURE 4 -- experimental and - simulated reflectivity of $\mathrm{Al}_{2} \mathrm{O}_{3}$ (with ion bombardment) on polished silicon

Figure 3 shows the reflectivity curve of conventionally sputtered $\mathrm{Al}_{2} \mathrm{O}_{3}$. The Kiessig oscillations ${ }^{11}$ (contain the information of the film thickness) damp out at a scattering angle $\vartheta$ of about $1.0 \mathrm{deg}$., which is an indication of a rough film surface. The calculated reflectivity showed a mass density of about $3.170 \mathrm{~g} \mathrm{~cm}^{-3}$, a roughness of the substrate (silicon wafer) of about $6.0 \mathrm{~nm}$, and a film roughness of about 10.0 $\mathrm{nm}$. The thickness is discussed in section 3.3. Figure 4 shows the reflectivity curve of the $\mathrm{Al}_{2} \mathrm{O}_{3}$ film sputter-deposited during ion bombardment. The Kiessig oscillations are noticed at an angle $\vartheta$ of $1.8 \mathrm{deg}$. The model simulation shows a mass density of about $3.255 \mathrm{~g} \mathrm{~cm}^{-3}$ and a film roughness of about $4.5 \mathrm{~nm}$ at a substrate roughness of about $6.0 \mathrm{~nm}$. The ion bombardment leads to a structural change (see section 3.1.) and to a more dense $\mathrm{Al}_{2} \mathrm{O}_{3}$ film, which has a surface roughness smaller than the substrate roughness. This occurs because the deposited atoms get enough energy from the ions to arrange in positions that are energetically prefered.

Thus, a more dense $\mathrm{Al}_{2} \mathrm{O}_{3}$ film grows at low substrate temperature, which has a crystalline structure and a low surface roughness.

\subsection{Comparison of Thickness Measurements}

$\mathrm{X}$-ray reflectivity is an integral method to determine the film thickness. The ellipsometry and the stylus method are used for local characterization, and measurements were made at several points in the samples center. The average values are given in Table $\mathrm{I}$, and the results of the two samples selected for presentation are representative for all samples we investigated. Table I shows a good correlation in thickness. The following observation should be mentioned: $\mathrm{Al}_{2} \mathrm{O}_{3}$ films with contaminations like Al-clusters falsify the ellipsometry data and result in lower values of thickness compared with reflectivity data and stylus thickness. 
TABLE I

Thickness $\mathrm{d}$ measured by ellipsometry, stylus method and x-ray reflectivity

\begin{tabular}{l|ccc}
\hline $\begin{array}{c}\text { method } \\
\text { material }\end{array}$ & $\begin{array}{c}\text { ellipsometry } \\
\mathrm{d} \text { in } \mathrm{nm}\end{array}$ & $\begin{array}{c}\text { stylus } \\
\mathrm{d} \text { in } \mathrm{nm}\end{array}$ & $\begin{array}{c}\text { reflectivity } \\
\mathrm{d} \text { in } \mathrm{nm}\end{array}$ \\
\hline $\mathrm{Al}_{2} \mathrm{O}_{3}$ (conv.) & $71.0( \pm 0.1)$ & $71.0( \pm 0.5)$ & $69.0( \pm 0.1)$ \\
$\mathrm{Al}_{2} \mathrm{O}_{3}$ (ion) & $75.0( \pm 0.1)$ & $74.0( \pm 0.5)$ & $74.3( \pm 0.1)$ \\
\hline
\end{tabular}

\section{CONCLUSION}

The reactive sputter deposited $\mathrm{Al}_{2} \mathrm{O}_{3}$ films prepared in this work are suitable for passivation in thin film circuits. A permanent magnet mounted above the substrate causes a small amount of ion bombardment to the growing $\mathrm{Al}_{2} \mathrm{O}_{3}$ film.

The ion bombardment results in a mass density, refractive index, and dielectric constant larger than those of conventional sputter deposited $\mathrm{Al}_{2} \mathrm{O}_{3}$ films. The surface roughness of the film becomes lower than that of the substrate.

Thus, these films are preferred for electrical and optical applications. The structure of the film deposited with ion bombardment was determined as $\gamma-\mathrm{Al}_{2} \mathrm{O}_{3}$.

It must be emphasized that the ion bombardment leads to a structure that can be obtained normally at high substrate temperatures (much more than $100{ }^{\circ} \mathrm{C}$ ), and we conclude an equivalence of ion bombardment and higher substrate temperature.

The comparison of the thickness determined by ellipsometry, stylus, and x-ray reflectivity does not show significant differences.

\section{ACKNOWLEDGEMENT}

The authors are thankfull to Dr. Th. Gerber and Dr. G. Holzhüter (University of Rostock) who gave them the possibility to do the transmission electron diffraction study and $x$-ray reflectivity study.

\section{REFERENCES}

1. R.A. Abott, T.I. Kanins, Solid State Electron. 13 (1970) 565.

2. E. Este, W.D. Westwood, J. Vac. Sci. Technol. A2(3) (1984) 1238.

3. M. Scherer, P. Wirz, Thin Solid Films 119 (1984) 203.

4. A.G. Spencer, R.P. Howson, R.W. Lewin, Thin Solid Films 158 (1988) 141.

5. R. Manaila. A. Derenyi, E. Candet, Thin Solid Films 116 (1984) 289.

6. H.E. Göbel, ECS Symposium joint with ESSDERC, proc., Berlin (1989).

7. L.G. Paratt, Phys. Rev., 95 (2) (1954) 359.

8. B. Vidal and P. Vincent, Appl. Opt. 23, 1794 (1984).

9. E.S. Wu, W.W. Webb, Phys. Rev., A8(4) (1973) 2065.

10. A.V. Andreev, A.G. Michette, A. Renwick, J. of Mod. Optics 35 (10), 1667-87 (1988).

11. H. Kiessig. Ann. d. Physik, 10 (1931) 715. 

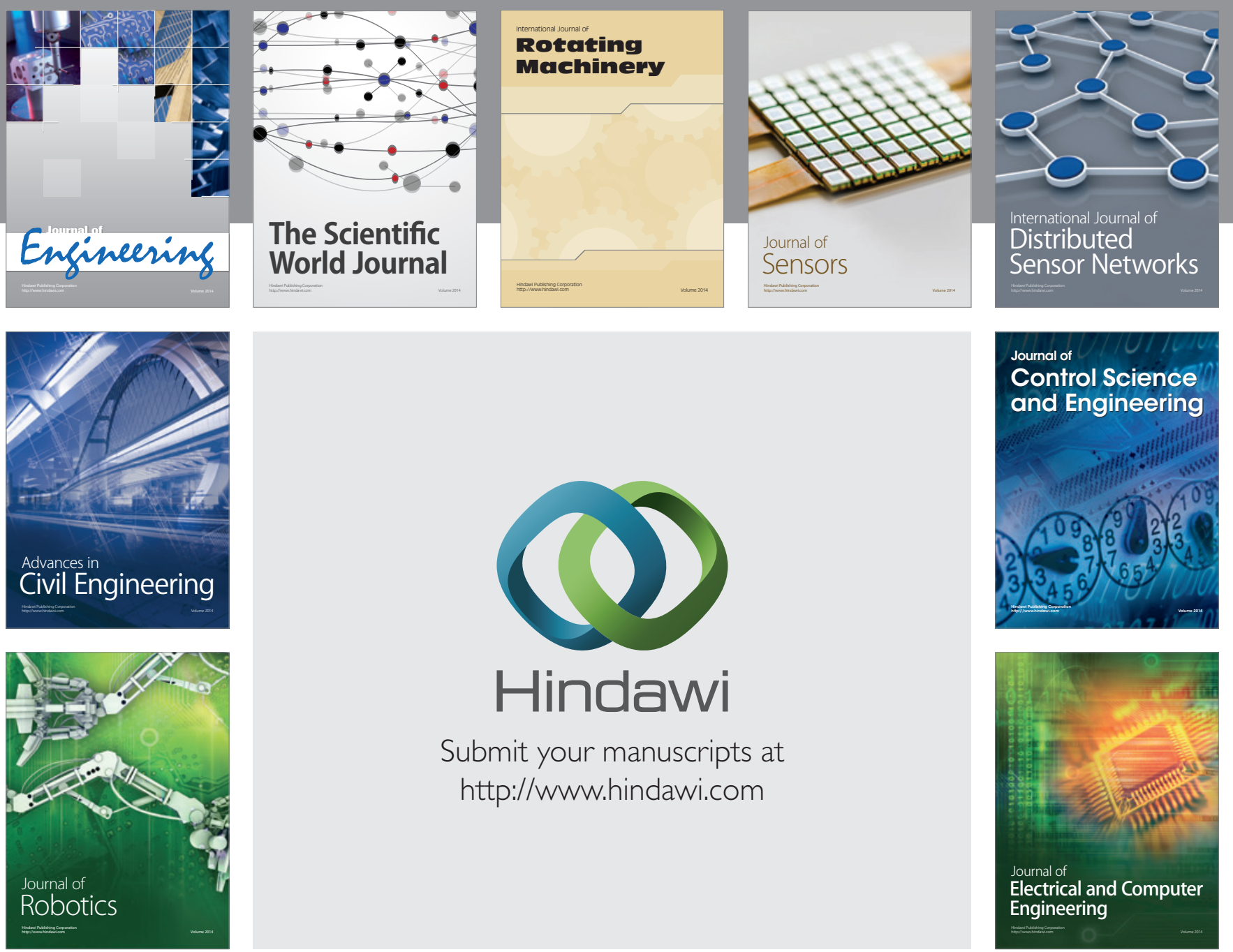

Submit your manuscripts at

http://www.hindawi.com
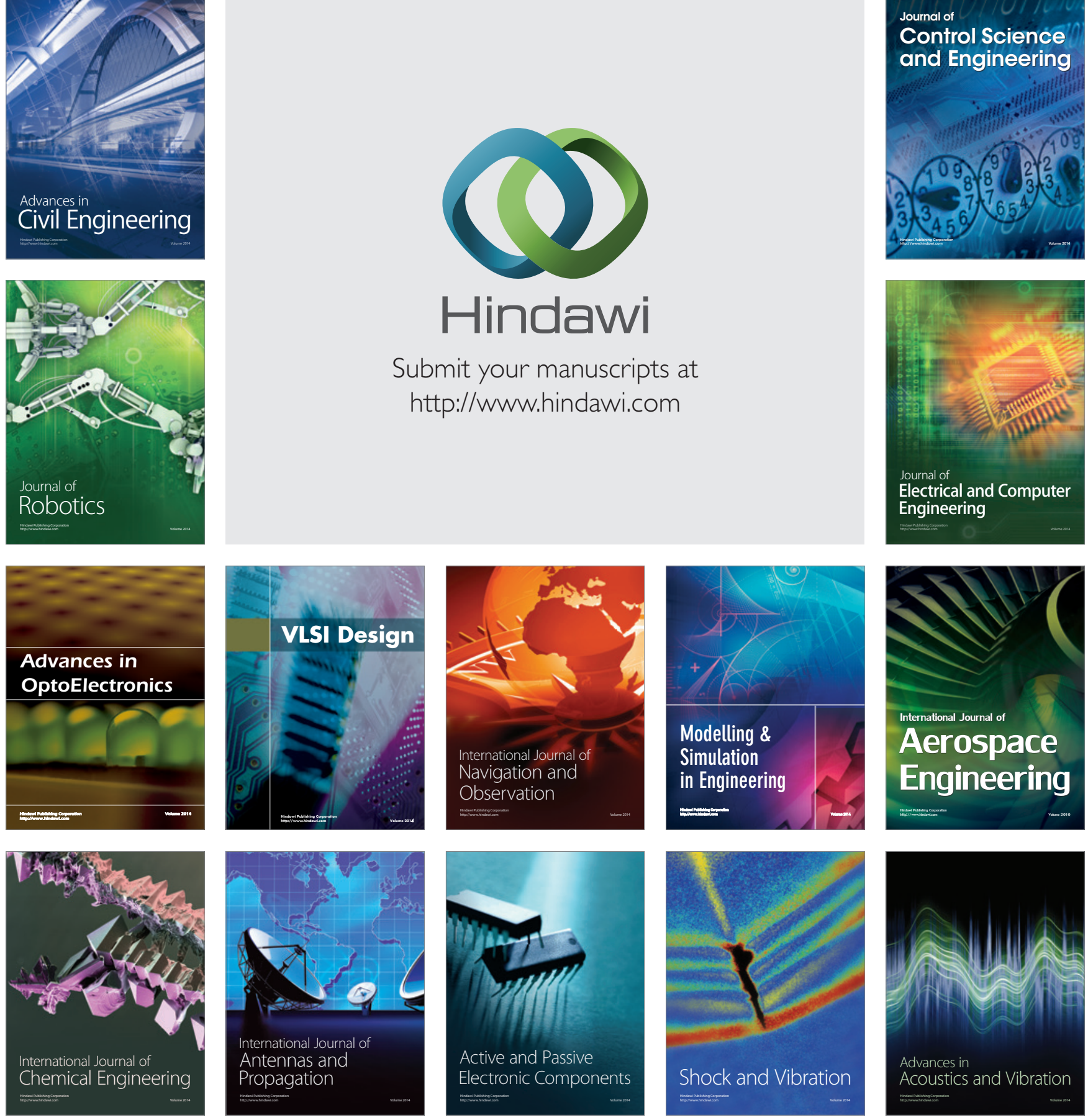